\title{
Melt pond formation and temporal evolution at the drifting station Tara during summer 2007
}

\author{
Paula Sankelo, ${ }^{1}$ Jari Haapala, ${ }^{2}$ István Heiler ${ }^{2}$ \& Eero Rinne ${ }^{3}$ \\ 1 Department of Geographical and Earth Sciences, University of Glasgow, Gregory Building, Lilybank Gardens, Glasgow, G12 8QQ, UK \\ 2 Finnish Meteorological Institute, PO Box 503, Fl-00101 Helsinki, Finland \\ 3 School of GeoSciences, University of Edinburgh, Drummond Street, Edinburgh, EH8 9XP, UK
}

\section{Keywords}

Albedo; melt pond; sea ice.

\section{Correspondence}

Paula Sankelo, Department of Geographical and Earth Sciences, University of Glasgow, Gregory Building, Lilybank Gardens,

Glasgow, G12 8QQ, UK. E-mail:

paula.sankelo@ges.gla.ac.uk

doi:10.1111/j.1751-8369.2010.00161.x

\begin{abstract}
Melt pond coverage of sea ice in the High Arctic was observed for a period of 28 days: from 24 June to 21 July 2007. Pond fractions were computed from digital photographs automatically obtained with a camera and computer unit mounted in the mast of the drifting polar schooner Tara. The area visible in the series of images corresponds to approximately $6400 \mathrm{~m}^{2}$ on the ice. By applying iterative image classification methods, the images were partitioned into melt ponds and other surface types, such as ice or snow. The percentage of melt ponds could be calculated for 22 out of 28 days. Six days were omitted from the analysis because of weather conditions causing poor visibility. Melt pond coverage was seen to rise rapidly shortly after the melt ponds started forming: between 24 and 30 June 2007 the pond fraction increased from 3 to $14 \%$. After the first rapid growth period, the pond fraction increased more gradually, reaching $15 \%$ at the end of the data collection period (21 July 2007). Estimated with additional data, the maximum melt pond coverage was reached in midAugust, and totalled $32-42 \%$. Melt onset date and the initial rapid melt pond growth agree well with previous research, but the areal pond coverage appears surprisingly high for the latitude $\left(88^{\circ} \mathrm{N}\right)$. Direct comparison with previously observed melt pond coverage is rendered difficult by scarce observations of pond coverage sufficiently high up in the Arctic.
\end{abstract}

Sea-ice albedo is one of the key parameters in the climate system. When temperatures rise in the summer, sea ice and the snow on top of it start to melt. Melt pond formation lowers the regional surface albedo of sea ice, because water has a significantly lower albedo than either snow or ice. As the surface albedo of sea ice diminishes, even more short-wave radiation is absorbed in the ice. This further enhances the melting, which again lowers the regional albedo. This process-the sea-ice albedo feedback mechanism-is suspected to amplify climate warming in the polar regions. Conversely, a downward trend in global temperature would increase sea-ice albedo, which would in turn accelerate cooling (e.g., Curry et al. 1995; Curry et al. 2001; Pedersen et al. 2009.)

In its simplest form, the sea-ice albedo feedback mechanism operates by decreasing snow- and ice-covered areas as a result of warming. However, different sea-ice models have shown that the sea-ice albedo feedback also oper- ates on multiyear ice. Even if an ice floe survives the melting season, it will still respond to the increase in summer temperatures. Curry et al. (1995) have discussed the internal transformation processes that contribute to the sea-ice albedo feedback mechanism on multiyear ice. Such processes include the melting of snow cover, diminishing of total ice thickness, opening of leads and the formation of melt ponds in the summer (Curry et al. 1995).

It is clear that the number of melt ponds markedly affects sea-ice albedo. For example, based on the results of the Surface Heat Budget of the Arctic (SHEBA) campaign carried out in the Beaufort Sea, Perovich, Grenfell et al. (2002) estimated that the total albedo of multiyear sea ice dropped from 0.8-0.9 in April to 0.4 in August, mainly as a result of melt pond formation. When modelling the sea-ice albedo feedback, and its climatic effects on polar regions, it is important to have data on melt pond 
coverage on multiyear sea ice from various locations in the Arctic sea. (Multiyear sea ice is scarce in Antarctic regions.)

Photographs, aerial or otherwise, are one possible means of studying the melt pond coverage on a region of ice. The areal extent of melt ponds can also be assessed by direct measurements performed on the ice: for example, by setting up a survey line and measuring the extent of melt ponds along the line (e.g., Perovich, Grenfell et al. 2002). The advantage of photographic data is that they allow the melt pond coverage to be obtained from a significantly larger area than could be examined directly on the ice. Perovich, Grenfell et al. (2002) have also shown that there is indeed good agreement between melt pond coverage measured directly on ice and melt pond coverage obtained from photographic data of the same region.

Several previous studies have obtained pond coverage from various photographic data sets (e.g., Hanson 1961; Langleben 1969, 1971; Eicken et al. 1996; Derksen et al. 1997; Perovich \& Tucker 1997; Tschudi et al. 1997; El Naggar et al. 1998; Fetterer \& Untersteiner 1998; Tucker et al. 1999; Tschudi et al. 2001; Perovich, Tucker et al. 2002; Markus et al. 2003; Tschudi et al. 2008). Before the time of digital image processing, pond areas were measured from film photographs with a planimeter (Langleben 1969, 1971). From the 1990s onwards, modern digital image processing techniques have been used to obtain the melt pond coverage from digitized photographs.

The distinction of melt puddles from surrounding ice (and possibly open water) can be attempted in several different ways. Some authors, working with digital greyscale images, have manually selected a suitable brightness threshold to separate ponds from their surroundings (Eicken et al. 1996; Derksen et al. 1997; El Naggar et al. 1998). Others (Tschudi et al. 1997, 2001; Markus et al. 2003; Tschudi et al. 2008) have used colour images, and utilized the fact that the melt pond spectral albedos tend to be highest in the blue end of the optical wavelength region. Yet another way of partitioning images of ice into different surface types is to use automated classification algorithms. Fetterer \& Untersteiner (1998) have used supervised classification with manually selected training areas to distinguish melt ponds in photographs.

Although melt pond coverage on multiyear ice has been studied to a reasonable extent over a period of more than four decades, no simple generalizations can be made based on the available results. This is partly because of the aforementioned fact that research campaigns in the Arctic are difficult and costly. It is not easy to obtain melt pond observations that cover a large areal extent and span a reasonably long time frame. The greatest number of aircraft- or ground-based melt pond measurements have been performed in the Beaufort and Chukchi seas, and those results cannot necessarily be generalized for the whole Arctic region. There is still demand for further research on melt pond coverage in diverse regions of the Arctic, especially in the central Arctic Basin. The melt season of 2007 is especially interesting because of the sea-ice extent minimum that occurred in 2007.

\section{Summer 2007 sea-ice extent minimum}

The pack ice of the Arctic Ocean has experienced remarkable shrinking and thinning in the last two decades. The most apparent changes are in the average and annual minimum sea-ice extents (Comiso et al. 2008), and in the mean sea-ice thickness (e.g., Rothrock et al. 1999; Haas et al. 2008; Kwok \& Rothrock 2009). The residence time of the sea ice in the Arctic has also shortened (Maslanik, Fowler et al. 2007). These observations indicate that the changes in Arctic pack ice are the result of changes in both thermodynamical and dynamical driving factors, connected with global warming enhanced by humaninduced greenhouse gas emissions. Even in this context, the loss of sea ice during summer 2007 was exceptional. In September 2007, the minimum ice extent was only $4.3 \times 10^{6} \mathrm{~km}^{2}$ (Stroeve et al. 2008), which was approximately $2.5 \times 10^{6} \mathrm{~km}^{2}$ less than the average Arctic sea-ice extent in the period 1979-2000.

Reasons for the 2007 sea-ice extent minimum have been discussed in several recent studies. One important factor was preconditioning, a continuous decrease of ice thickness, but the main driving force seems to have been an anomalous atmospheric circulation. During summer 2007, a high sea-level pressure cell persisted over the western Beaufort Sea and northern Canada. At the same time, sea-level pressure over Siberia and Europe was anomalously low. This circulation mode is known as the Dipole Anomaly (Wang et al. 2009). It leads to southerly winds over the western Beaufort, Chukchi and East Siberian seas, bringing warm air masses to the area (Vihma et al. 2008), and increasing the northward transport of ice from it (Maslanik, Drobot et al. 2007; Zhang et al. 2008; Wang et al. 2009). Kwok (2008) has reported an increased ice flow from the Pacific to the Atlantic sector of the Arctic Ocean during the summers of 2006 and 2007, contributing to sea-ice loss in the Pacific sector. The persistent high sea-level pressure over the western Arctic in summer 2007 also led to reduced cloud cover, which enabled more shortwave radiance to reach the ice (Kay et al. 2008).

The anomalous sea-ice transport pattern appears to have strengthened the ice albedo feedback mechanism and enhanced melting, especially at the bottom of the ice. 
Zhang et al. (2008) estimated that approximately 30\% of the sea-ice loss was directly related to anomalous ice advection, whereas $70 \%$ was the result of enhanced melting.

\section{Methods}

\section{Instrumentation}

On 3 September 2006, a French private schooner Tara and her crew set out to repeat the famous voyage of Nansen's ship Fram. Tara was anchored in the pack ice off the coast of Siberia, north of the Laptev Sea. Drifting with the ice, Tara reached her northernmost point $\left(88^{\circ} 32^{\prime} \mathrm{N}\right)$ on 28 May 2007, and exited the pack ice on the west side of the Greenland Sea on 21 January 2008 (Gascard et al. 2008.)

In spring 2007 Tara hosted a research camp for the European scientific programme Developing Arctic Modeling and Observing Capabilities for Long-term Environmental Studies (DAMOCLES). As a part of the monitoring programme we deployed an automatically functioning camera and computer unit in the mast of Tara. The unit was assembled by a Finnish group who in 2008 formed a commercial, scientific digital photography company (Vogon-IT). The camera unit consisted of a consumer-grade digital camera, a computer and a global positioning system instrument, all placed inside a protective casing. The unit was mounted on the mast of Tara, approximately $7 \mathrm{~m}$ above the ice surface. It stayed operational from 29 April to 22 July 2007, automatically obtaining a photograph every $10 \mathrm{~min}$. Photographs were stored on the hard disk of the computer, until the unit was dismounted and the photographs were retrieved. The physical area uniformly covered in the resulting time series of photographs corresponds to $6390 \mathrm{~m}^{2}$ on the ice, with a resolution of the perspective-corrected photographs equalling $5 \times 5 \mathrm{~cm}$ (Fig. 1).

About two months after the camera was set up the first signs of melt ponds appeared, on 19 June 2007. For unknown reasons, the camera stopped functioning on 22 July 2007, when the melt period was still well underway. The whole melt season was thus not captured on the photographic data set. However, a data set covering approximately one month of the melt season is still of great interest, especially when obtained from pack ice at $88^{\circ} \mathrm{N}$, and during the melt season of 2007 .

\section{Image correction}

Before the analysis of the images could start, several corrections were needed on the original data. First of all, barrel distortion and other possible geometric lens distor-

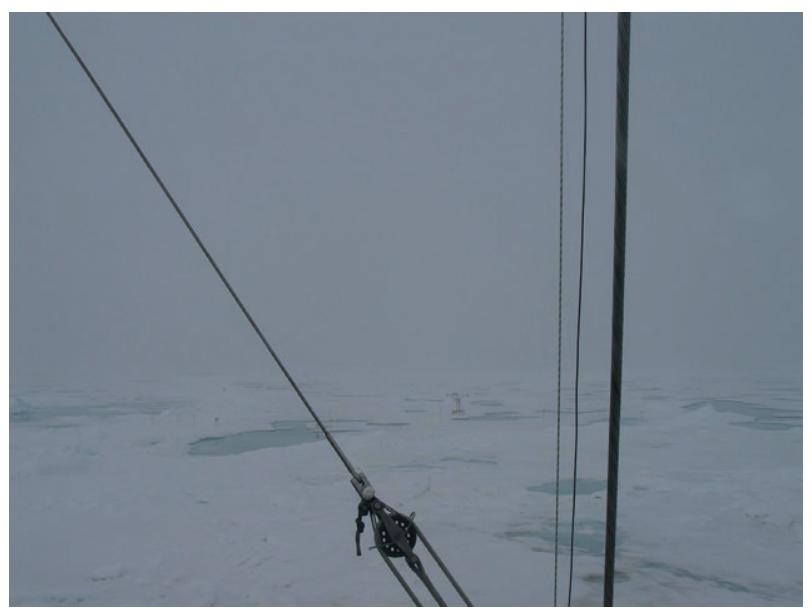

Fig. 1 A barrel distortion-corrected image of the study area on a cloudy day, 20 July 2007.

tions were removed with the help of a grid image taken by the camera in question. Lens distortions were in this case small, too slight to be detected by eye. Unwanted portions of the image were cropped out: these included the sky and a strip of ice near the ship that had been frequently trampled on. Some rigging of the ship was visible in the images, but as these later formed their own distinct spectral class, their effect could be removed after the classification.

The most crucial correction performed on the images was perspective correction. Whereas barrel distortion and other lens distortions are caused by the specificities of the camera optics, perspective distortion is a function of geometry, not the camera. In a photograph, distant objects seem smaller than those close by, precisely as is the case with human visual perception. Thus, different areas in the same photograph cannot be compared with each other, unless the image is rectified so that every image pixel corresponds to an equally large physical area. An automated programme was created to eliminate the perspective distortion and to convert the images to the horizontal plane, corresponding to real physical distances on the ice (Heiler unpubl. ms.). The area captured in the time series is comparable with a rectangle of approximately $80 \times 80 \mathrm{~m}$, although because of the photographic perspective, the shape of the area is in fact a trapezoid (Fig. 2a).

Tara shifted her position in the pack ice several times, changing the height of the camera from the ice surface. This introduced some complications to the image rectifying process, and acted as a source of error. As the height of the camera at any given time was not precisely known beforehand, the rectification would have in fact proved impossible had there not been convenient calibration 

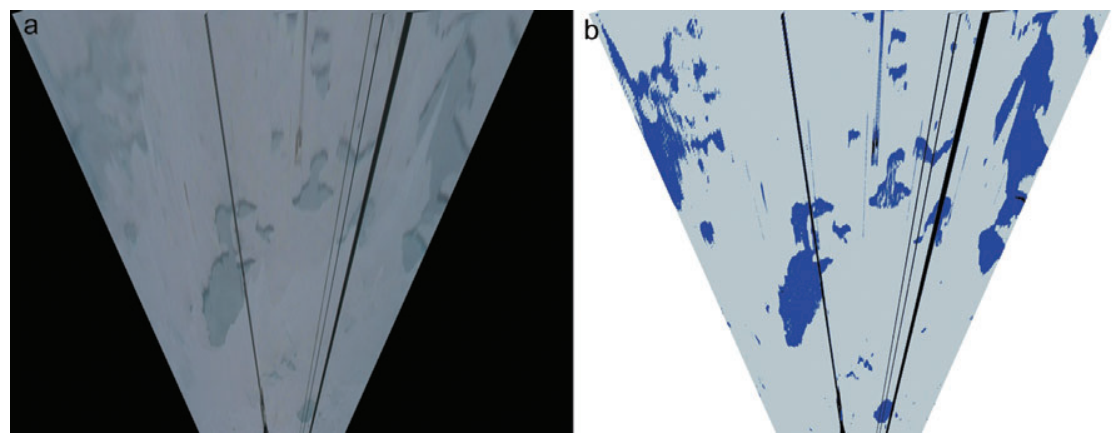

Fig. 2 (a) A geometrically-corrected image with sky and foreground removed, 20 July 2007. (b) The classified image, 20 July 2007. Rigging of the ship and instruments form their own spectral class on ice (coloured black), with some overlap with the very darkest areas of the ponds (coloured blue). Four spectral classes were needed to create this classification (rigging, ponds and two types of ice).

points (snow depth measurement poles) visible in the photographs. The height of the camera needed to be calculated anew, with the help of the known calibration points, for each time the ship did shift her attitude. After the height of the camera was found out, the rectification algorithm could be performed for each image.

\section{Image classification}

The geometrically rectified photographs were partitioned into melt ponds and ice (bare or snow-covered) by unsupervised classification (Fig. 2b). Image classification was performed by iteratively arranging the spectral vectors of an image into a given number of separate clusters. These clusters are called spectral classes, and in remote sensing applications they normally correspond with different types of terrain. Separate land cover or land use categories—such as forest, field, rock, ice, sweet water, salt water and urban areas-all have a specific spectral signature, although some overlap may occur between the spectral signatures of different classes (e.g., Neteler $\delta$ Mitasova 2002.)

In this study, the spectral vectors being clustered were points in three-dimensional red-green-blue (RGB) colour space making up the colour images taken by a digital camera. In general, the wavelength bands used in image classification need not be red, blue and green, nor do they need to lie in the visible region at all. The wavelength bands being used in the analysis depend on the imaging instrument and the aims of the study. Water absorbs infrared radiation a lot more effectively than snow or ice, and thus it might be beneficial to use an infrared band for the detection of ponds on ice. The instrument used in this study, however, did not allow for that option.

The classification of images was performed using Geographic Resources Analysis Support System (GRASS) software, a free, open-source geographical information system, with some additional accuracy checks performed using OPENEV open-source software. Both supervised and unsupervised classification methods were tried, as well as alternative methods of partitioning the image. Those included choosing a suitable brightness threshold level to separate ponds from ice, and exploiting the difference between the blue and the red channels. Unsupervised classification was deemed to produce the most reasonable results, and to be somewhat less prone to observer bias than other methods that were tried.

Weather and illumination conditions affected both the classification procedure and the resulting accuracy. On sunny days the snow and ice features protruding from the ice could be seen to cast shadows. The spectral signature of bluish shadows on snow was similar to that of the blue melt ponds, causing overlap with ponds. Direct sunlight also brought forth more details from the snow and ice (e.g., surface roughness), adding to the number of spectral classes needed for a successful classification. On a cloudy day, with dull illumination, the unponded ice had, overall, a more uniform appearance. This effect was aided by the fact that during cloudy periods it often snowed, and freshly fallen snow temporarily rendered the ice surface more uniform.

When performing the image classification for sunny days, typically one or two more spectral classes were needed than for cloudy days. The extra spectral classes allowed for the pond pixels and shadow pixels to fall into different spectral classes, instead of the same one. However, some pond/shadow overlap remained even in the most successful classifications for sunny days, rendering the classification somewhat less accurate for sunny images than for cloudy ones. The fact that spectral reflectance of both ponds and ice surfaces vary intrinsically according to illumination conditions did not introduce further difficulties to the classification: shadows on the ice were by far the greatest challenge. To eliminate the possible unwanted effects springing from changing illumination conditions, we only analysed images taken at local noon.

It must be stressed that without any additional data from the same region, such as direct melt pond coverage measurements made on the ice, the absolute error of the classification results cannot be reliably established. The 

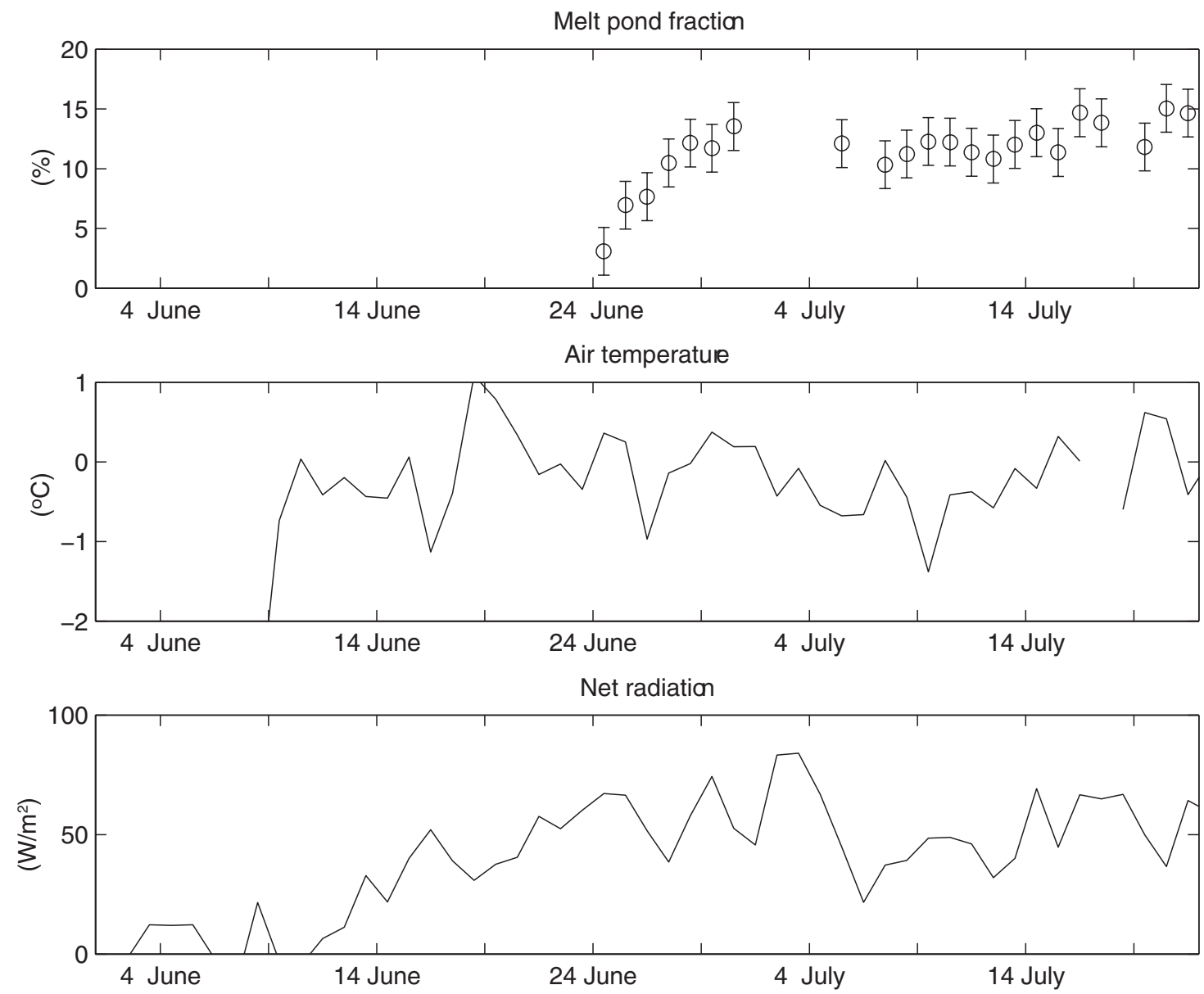

Fig. 3 Melt pond fraction, air temperature and net radiation measured at Tara in June-July 2007.

accuracy of the partitioning results was in this case estimated by first of all comparing the partitioning results with the original photographs. When the partitioning method seemed to produce a reasonable distribution of melt ponds, additional checks were performed by using the same partitioning methods with different software, establishing that different classification algorithms produced similar results with the same number of spectral classes chosen. The error assessment will be discussed more extensively below.

\section{Results}

\section{Melt pond coverage}

Figure 3 presents melt pond fractions calculated from the classified images, alongside surface air temperature and net radiation. Melt pond coverage was obtained for 22 days during the data collection period. Only one classified image per day was produced. The images chosen for clas- sification were all taken at local noon, so that the illumination conditions from one chosen photograph to the next might vary as little as possible. The choice had more to do with the direction of the sun than its elevation, which does not vary greatly during midsummer at such high latitude. (For the same reason, no diurnal cycle in pond area was observed in the photograph set.) Six noon images out of 28 were discarded because of weather conditions causing very poor visibility.

The Tara atmospheric monitoring programme included air temperature, wind speed, upward and downward short- and long-wave radiation measurement and tethersonde soundings (Vihma et al. 2008). The air temperature was measured $2 \mathrm{~m}$ above the ice surface. The net radiation data used in this study is the sum of all the radiation components. The weather station was located approximately $100 \mathrm{~m}$ from the monitoring area of the melt ponds.

Emergence of the first melt ponds was preceded by a preconditioning period of 2 weeks, when the radiation 


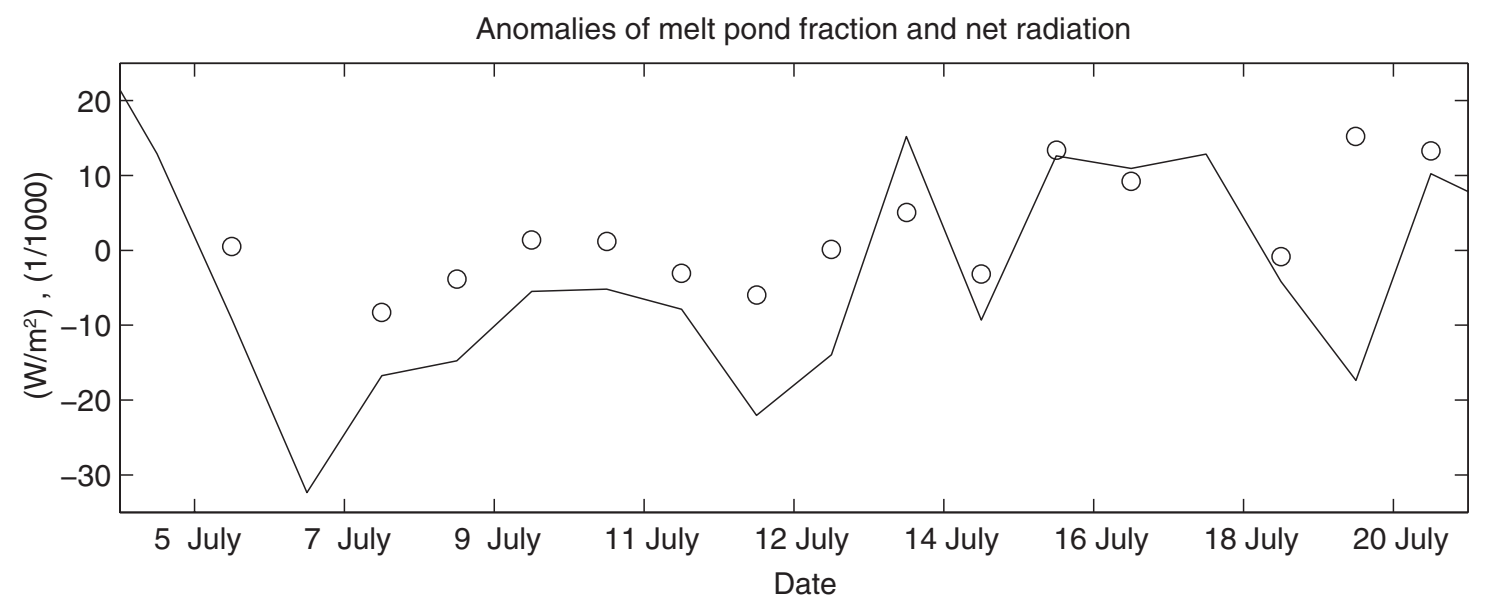

Fig. 4 Daily mean net radiation (line) and melt pond fraction (circle) anomalies during 5-21 July 2007.

balance turned positive. At the time of the summer solstice, the daily mean net radiation was $50-70 \mathrm{~W} \mathrm{~m}^{-2}$. The mean air temperature was mostly negative during the preconditioning period, but during 17-19 June it was above zero throughout the day.

Slight depressions on the snow cover are first observable on the 19 June 2007 image, indicating the spots where the first melt ponds appear. The first distinct melt ponds formed on 21 June 2007. The two tiny ponds in the 21 June image are too small to be distinguished as a separate spectral class, and no reliable estimate on melt pond coverage is obtained until 24 June 2007, when the melt pond coverage had reached $3 \%$. The camera was operational until the early morning of 22 July 2007, and thus noon images have been obtained for a period of 28 days. Out of those 28 days, melt pond coverage has been calculated for 22 days.

Although the very onset of melt is not captured by the classification algorithm, it can be estimated based on the acquired images that the melt pond fraction increased from 0 to $3 \%$ in 5 days (20-24 June 2007). During that time, the melt pond fraction grew by approximately $0.6 \%$ every day. From 24 June 2007 onwards, the growth rate more than doubled: the melt pond fraction increased from $3 \%$ to approximately $14 \%$ in 7 days.

After 30 June 2007 there's an unfortunate gap in the data: images from 1 to 4 July 2007 could not be geometrically corrected because of foggy and snowy weather conditions. Images from those days are still clear enough to form an estimate that the rapid phase of the melt did indeed end on 30 June 2007. The melt pond fraction stopped growing significantly and started to fluctuate around $12 \%$ for approximately 2 weeks (1-15 July 2007).

During that period, the daily mean air temperature was always below $0^{\circ} \mathrm{C}$. The mean net radiation was approxi- mately $50 \mathrm{~W} \mathrm{~m}^{-2}$, whereas the daily mean maximum and minimum net radiation levels were 84 and $22 \mathrm{~W} \mathrm{~m}^{-2}$, respectively. The day-to-day variations of melt pond fraction and net radiation were well correlated (Fig. 4). During the last days of the data collection period, the air temperatures were again above zero and the melt pond coverage increased slightly, reaching the vicinity of $15 \%$ by 21 July 2007.

It is likely that when the melt pond fraction had reached $15 \%$, the melt season was still well under way. Snow-depth data from Tara indicates that the snow level started rising again in mid-August. A snapshot taken by a crew member from Tara's mast on 20 August 2007 yields a melt pond coverage of $37 \pm 5 \%$. The estimate is relatively imprecise, as the height from which the image was taken is not known, and thus the image could not be rigorously rectified. However, we can conjecture that the maximum melt pond coverage was reached in August, and totalled more than $30 \%$.

\section{Estimated errors}

The error in the calculated melt pond fractions is estimated at $\pm 2 \%$ : that is, any given percentage is inaccurate by \pm 2 in percentage units (as opposed to the relative error being only $2 \%$, which is not the case here). It is important to stress that there is no reliable way of estimating the absolute error made in calculating the melt pond percentage, at least not without suitable auxiliary data to validate the results.

The classification success was assessed by first comparing the results with the original images. It was clear that a well-premeditated choice of parameters was needed for the classification to succeed at all, with the most important parameter being the number of spectral classes chosen. By changing the number of spectral classes 
chosen, it was often possible to produce more than one satisfactory classification result. The parameters that were chosen for each classification were the ones that seemed to produce the best result, compared with the original photographs.

The process of choosing the most satisfactory result is, or course, highly subjective and prone to errors. However, the results that clearly appeared satisfactory all fell within $\pm 2 \%$ of the result from the classification attempt deemed best: hence the choice of $\pm 2 \%$ for the error estimate. The OPENEV program was also employed to double check the results produced by GRASS GIS. The calculated melt pond fractions did fall inside the $\pm 2 \%$ margin, even when the classification was performed with another program. Some checks were also performed by using the alternative image-partitioning methods mentioned earlier, and their best-looking results again fell into the same $\pm 2 \%$ margin. To be cautious, a classification from a sunny day was used to quantify the error, as the classification was somewhat less accurate for sunny images.

There are multiple sources of error inherent in the image correction process, as well as in the classification itself. The physical parameters needed for image rectification were selected from images by hand, which means that they can hardly be absolute. The error inherent in such a process is difficult to quantify. Another type of inaccuracy arises from the ice topography itself. The ice surface is far from smooth: there are protruding features ranging from a small ridge to piles of snow. Higher parts of the ice field may block some low-lying features from the view of the camera. A numerical estimate of an error rising from this effect has not been attempted, because a reliable estimate would require more detailed knowledge of the ice topography on site.

\section{Discussion}

\section{Comparison with previous results}

Our results comprise three main aspects of interest: date of melt onset, early development of melt pond areas and absolute value of melt pond fraction. All three are compared with previous results from the Arctic, mainly those derived from photographic data sets. For a more thorough comparison, other types of melt pond measurements are also examined.

Melt onset. The date of melt onset is a parameter of great interest, because the quantity of solar energy absorbed into the ice-ocean system correlates more strongly with the melt onset date than with the overall length of the melt season. Melt pond formation affects the way the incoming solar radiation is partitioned into por- tions reflected by the ice, absorbed in the ice and transmitted through the ice. The way this partitioning is established early on in the season has a cumulative effect to the quantity of solar energy absorbed by the system throughout the season. If weather conditions trigger an early onset of melt, the energy budget of the system is influenced for the whole season (Perovich et al. 2007). During the SHEBA campaign, for example, melt onset was brought about by a rainfall event in late May (Perovich, Grenfell et al. 2002).

At Tara's location, $88^{\circ} \mathrm{N}, 124^{\circ} \mathrm{E}$, the first melt ponds appeared on 20 June 2007. Melt onset at Tara was not triggered by a precipitation event; on the contrary, it happened after a clear and sunny spell. Appearance of the melt ponds was preceded by a 2 -week period of positive radiation balance, and 3 days when the air temperature was above the freezing point of water.

According to ice mass-balance buoy (IMB) data acquired by Perovich et al. (2008), the melt season 2007 commenced in early June in the Beaufort Sea region. The melt season is expected to begin later at higher latitudes (e.g., Tschudi et al. 2008), and our result is in accord with that. IMBs deployed near the North Pole in the years 2000-05 have recorded snow surface melt-onset dates from 8 to 20 June, again in agreement with our result (Richter-Menge et al. 2006). In light of the IMB data, the onset of melt at Tara does not appear in any way exceptional, despite the anomalous weather and ice conditions in the Arctic during summer 2007.

It is worth noting that near Tara the snow did not melt completely during the period of observation: by 21 July 2007 the unponded ice was still covered by snow. Although IMBs deployed near the North Pole in 2000-05 typically recorded snow surface melt onsets in mid-June, the snow cover melted away on average in mid-July, if at all (Richter-Menge et al. 2006). Again, this is in line with our results.

Early pond evolution evolution. The rapid growth of the melt pond fraction shown in Fig. 3 is immediately comparable with previous melt pond studies (e.g., Derksen et al. 1997; Perovich, Tucker et al. 2002; Tschudi et al. 2008). Quoting from Perovich, Tucker et al. (2002: 24-27): "In mid-June ponds cover a few percent of the ice, but then, in just a few days, between 15 and 18 June, [pond fraction] jumps by a factor of five from 0.04 to 0.20 ". This is very much in accord with the temporal evolution observed near Tara: the pond fraction increased by approximately a factor of 4.5 (from 3 to $14 \%$ ) within a week.

It is not surprising that the melt pond fraction should rise steeply soon after the ponds have started forming. When the wet snow on top of the ice starts melting, there 
Table 1 Melt pond fractions computed from various photographic data sets in the Arctic. Pond fractions are expressed as the fraction of ponded compared with unponded ice.

\begin{tabular}{|c|c|c|c|}
\hline Author & Location & Date & Pond fraction from photographic data \\
\hline \multirow{2}{*}{ Eicken et al. 1996} & \multirow[t]{2}{*}{ Eurasian Arctic } & 2 days in August 1991 & Average of 16\% in 1991 \\
\hline & & 4 days in August 1993 & Average of 19\% in 1993 \\
\hline Derksen et al. 1997 & $\begin{array}{l}\text { Canadian Arctic Archipelago } \\
\left(\text { ca. } 74^{\circ} \mathrm{N}\right)\end{array}$ & 7-9 July 1995 & Maximum of $53 \%$ \\
\hline Perovich et al. 1997 & $76^{\circ} \mathrm{N}, 172^{\circ} \mathrm{W}$ & 31 July 1994 & Average of $12 \%$ \\
\hline Tschudi et al. 1997 & Beaufort Sea $\left(c a .72^{\circ} \mathrm{N}\right)$ & 12 September 1994 & Average of $20 \pm 8 \%$ \\
\hline El Naggar et al. 1998 & $\begin{array}{l}\text { Northeast Water Polynya } \\
\quad\left(\text { ca. } 78^{\circ} \mathrm{N}\right)\end{array}$ & 6-30 July 1993 & $\begin{array}{l}34.2 \pm 14.26 \% \text { on }\left.\mathrm{FY}\right|^{\mathrm{a}} \\
19.0 \pm 6.85 \% \text { on } \mathrm{MYl}^{\mathrm{b}}\end{array}$ \\
\hline \multirow[t]{3}{*}{ Fetterer \& Untersteiner 1998} & \multirow[t]{3}{*}{ Beaufort Sea } & July 1993 & $40-50 \%$ on $F Y l^{a}$ \\
\hline & & July \& August 1994 & $30 \%$ on $\mathrm{MYI}^{\mathrm{b}}$ \\
\hline & & Entire summer 1995 & \\
\hline \multirow[t]{3}{*}{ Tucker et al. 1999} & \multirow[t]{3}{*}{ Arctic Ocean $\left(76^{\circ} \mathrm{N}-88^{\circ} \mathrm{N}\right)$} & 31 July 1994 & $12 \%$ at $76^{\circ} \mathrm{N}$ (31 July) \\
\hline & & 13 August 1994 & $3 \%$ at $84^{\circ} \mathrm{N}$ (13 August) \\
\hline & & 18 August 1994 & Only frozen ponds at $88^{\circ} \mathrm{N}$ (18 August) \\
\hline \multirow[t]{2}{*}{ Yackel et al. 2000} & \multirow[t]{2}{*}{ Wellington Channel $\left(75^{\circ} \mathrm{N}, 93^{\circ} \mathrm{W}\right)$} & 30 June 1997 & ca. $10-20 \%$ along a transect, less on older/ \\
\hline & & 3 July 1997 & rougher ice \\
\hline Tschudi et al. 2001 & $\begin{array}{l}\text { Beaufort and eastern Chukchi Sea } \\
\left(\text { ca. } 78^{\circ} \mathrm{N}\right)\end{array}$ & 5 days in July 1998 & $\begin{array}{l}\text { Smallest } 24.6 \pm 6.2 \% \text { (8 July) } \\
\text { Largest } 34.1 \pm 8.4 \% \text { (24 July) }\end{array}$ \\
\hline Perovich et al. 2002 & Beaufort Sea & Twelve days in 5 Apr-4 Oct 1998 & Maximum of $24 \%$ (7 August) \\
\hline Markus et al. 2003 & Baffin Bay & 27 June 2002 & ca. $19-68 \%$ along a transect \\
\hline Tschudi et al. 2008 & $\begin{array}{l}\text { Beaufort and Chukchi seas } \\
\left(70^{\circ} \mathrm{N}-80^{\circ} \mathrm{N}\right)\end{array}$ & 13 June 2004 & $16.4 \%$ \\
\hline Perovich et al. 2009 & Arctic Ocean $\left(81^{\circ} \mathrm{N}, 177^{\circ} \mathrm{E}\right)$ & 22 August 2005 & Average of ca. $31 \%$ \\
\hline
\end{tabular}

a Multiyear ice.

${ }^{b}$ First-year ice.

is a rapid influx of water from the melting snow. This water will form melt pools, usually located in the depressions on the ice. Ponds have a lower albedo than the surrounding snow and ice, and thus they absorb more heat. The melt rate of ice beneath the ponds is two to three times higher than that of the ice surrounding the ponds. This implies that once the ponds have fully formed, the ongoing melt tends to take place under the melt pools, decelerating the growth of the pool diameter (Fetterer \& Untersteiner 1998).

Pond fraction. It is difficult to compare the absolute values of melt pond fractions with previous studies: the majority of previous melt pond coverage measurements have been made at different times and locations than the ones in this study. Our pond fraction time series begins on 24 June 2007, when Tara was at $88^{\circ} 11^{\prime} \mathrm{N}, 124^{\circ} 20^{\prime} \mathrm{E}$, and ends on 21 July 2007 at $87^{\circ} 56^{\prime} \mathrm{N}, 43^{\circ} 16^{\prime} \mathrm{E}$. There is scarce pond coverage data on multiyear ice that far north, and in any case there is a lot of interannual variability in the melt conditions.

Melt pond fractions computed from various photographic data sets are given in Table 1. Only results from the 1990s and onwards are included. In some cases results are much more detailed than the summary given here (i.e., a long transect with varying melt pond frac- tions). In some studies pond fractions were originally given as the fraction of ponded ice of the whole area photographed (i.e., ice + open water). In Table 1 we have expressed the pond fractions as the fraction of ponded compared with unponded ice. Markus et al. (2003) and Tschudi et al. (2008) have used aircraft data mainly as a validation tool for satellite-based melt pond fraction measurements, and reported further results for a larger study area and time range.

All in all, the results display a considerable variety. Our result of $15 \%$ by 21 July and more than $30 \%$ by midAugust on a multiyear floe are in line with most of the results presented in Table 1, and especially with those reported for multiyear ice. This may be rather surprising, bearing in mind that our results are obtained some $10^{\circ}$ further north than most previous studies. Tucker et al. (1999) did obtain photographic data at $88^{\circ} \mathrm{N}$ on 18 August 1994, and only frozen ponds were observed, with the melt season being over. Contrasted with our estimate of $37 \pm 5 \%$ pond coverage on 20 August 2007, the difference is striking, but comparison with one single date does not warrant far-reaching conclusions.

Melt pond fractions at latitudes comparable with this study have been estimated from on board a ship during two trans-Arctic cruises: the Arctic Ocean Section (AOS) in 1994 (Tucker et al. 1999) and the Healy Oden 
Trans-Atlantic Expedition (HOTRAX) in 2005 (Perovich et al. 2009). Aerial photographs from melt ponds were obtained in connection with both cruises, as indicated in Table 1, but on-board estimates from higher latitudes offer a more fruitful comparison here. At latitude band $85-90^{\circ} \mathrm{N}$ of the northward leg, in the late summer, both AOS and HOTRAX observed an average melt pond fraction of $6 \%$. AOS crossed the latitude band in August, and HOTRAX crossed in the first half of September. Our results again seem considerably larger, especially when contrasted with the AOS result of $6 \%$ in August.

\section{Representativeness of the site}

As seen in Table 1, the variability in reported melt pond fractions from the Arctic is great. It is well-documented that sea ice displays large spatial and temporal variability, and that the differences in ice morphology lead to different ponding extents and patterns. In general, first-year ice is smoother than multiyear ice, and tends to have larger pond fractions (e.g., El Naggar 1998; Fetterer \& Untersteiner 1998; Yackel et al. 2000; Perovich et al. 2009). Tschudi et al. (2008) have reported an increase in pond fraction with increasing latitude (at $70-80^{\circ} \mathrm{N}$ ), despite the fact that the melt season starts later further in the north. They attribute this to ice growing more abundant and predominantly thicker with increasing latitude, hence allowing for less meltwater run-off.

Because the thickness and overall morphology of ice play a large role in determining the melt pond fraction, and because sea ice is highly variable in these aspects, one must carefully consider the representativeness of the results obtained here. In the context of the Arctic Ocean, an area of $6400 \mathrm{~m}^{2}$ is but a point measurement. We argue, however, that the results can be extended to a larger area, especially where a similar ice type predominates.

Perovich \& Richter-Menge (2006) have examined the representativeness of IMB point measurements performed on multiyear ice. They conclude that a point mass-balance measurement can represent ice conditions on a larger area, provided the measurement site is correctly chosen. The argument is based on more than 100 ice mass-balance observations collected during the 1997-98 SHEBA campaign, covering an area of $100 \mathrm{~km}^{2}$. A wisely chosen point measurement site for mass-balance observation is a multiyear ice floe that is not deformed, and is of average size, compared with its neighbouring floes.

For the purposes of IMB measurements, the ice must also be "unponded": that is, the thermistor string should not be deployed directly at a melt pond site. The last condition cannot apply for the melt pond areal fraction measurement, but otherwise we believe the melt pond fraction measurements performed on a multiyear ice floe can be generalized with largely the same provisos as ice mass-balance measurements. After all, the criteria for IMB measurement sites have been selected so that the site itself should be representative of the perennial ice pack. If the criteria for a representative site are fulfilled, most likely the ponding on site is not highly anomalous either.

Our study area was located on a mainly multiyear ice floe that was of average size compared with its vicinity. Some new ice had been incorporated into the floe, where leads had previously opened, but this did not affect our study area. There were some protruding features in the camera view, including a smallish ridge ( $<2 \mathrm{~m}$ high), but generally the ice was not deformed. All in all, we believe our study area to be a representative one, at least in the context of the neighbouring ice floes, on the spatial scale of ca. $10 \mathrm{~km}$. Our conclusion is aided by the fact that, despite our rather limited study area, both the date of melt onset and the early development of melt ponds agree well with previous results. This fosters the belief that the pond evolution on site was not anomalous.

In conclusion, the timing of melt onset and the subsequent rapid pond growth accord well with previous studies. The absolute values of melt pond coverage near Tara seem higher than expected, insofar as comparison with previous studies is possible. The exceptional sea-ice melt conditions of summer 2007 may be reflected in the melt pond coverage results presented here, but we cannot absolutely conclude that. It should be borne in mind that melt onset did not happen especially early, and IMB point measurement data from the North Pole region show no significant increase in either surface or bottom melt during the summer of 2007 (Perovich et al. 2008).

\section{Acknowledgements}

This study was supported by the European Union FP6 integrated project DAMOCLES. The crew of Tara and the Tarawaka logistics group are thanked for their realization of the field programme. We also thank the Karhukamera team, led by Mikko Viitapohja, and Vogon-IT Ltd. for providing the time-lapse unit for this study. The Tara meteorological observations were made by Jaak Jaagus, Erko Jakobson, Timo Palo and Timo Vihma. The expedition was led by Etienne Bourgois, and was sponsored by the fashion company agnés b. Comments by two anonymous reviewers greatly improved this paper and are gratefully acknowledged.

\section{References}

Comiso J.C., Parkinson C.L., Gersten R. \& Stock L. 2008. Accelerated decline in the Arctic sea ice cover. Geophysical Research Letters 35, L01703, doi: 10.1029/2007GL031972. 
Curry J.A., Schramm J.L. \& Ebert E.E. 1995. Sea ice-albedo climate feedback mechanism. Journal of Climate 8, 240-247.

Curry J.A., Schramm J.L., Perovich D.K. \& Pinto J.O. 2001. Applications of SHEBA/FIRE data to evaluation of snow/ ice albedo parameterizations. Journal of Geophysical Research-Atmospheres 106, 15 345-15 355.

Derksen C., Piwowar J. \& LeDrew E. 1997. Sea-ice melt pond fraction as determined from low level aerial photographs. Arctic and Alpine Research 29, 345-351.

Eicken H., Gradinger R., Ivanov B., Makshtas A. \& Pác R. 1996. Surface melt puddles on multi-year sea ice in the Eurasian Arctic. In P. Lemke et al. (eds.): Proceedings of the ACSYS Conference on the Dynamics of the Arctic Climate System: Göteborg, Sweden, 7-10 November 1994. WCRP 94. Pp. 267-271. Geneva: World Meteorological Organization.

El Naggar S., Garrity C. \& Ramseier R.O. 1998. The modelling of sea ice melt water ponds for the High Arctic using an airborne line scan camera, and applied to the Satellite Special Sensor Microwave/Imager (SSM/I). International Journal of Remote Sensing 19, 2372-2394.

Fetterer F. \& Untersteiner N. 1998. Observations of melt ponds on Arctic sea ice. Journal of Geophysical Research-Oceans 103, 24 821-24835.

Gascard J.-C., Festy J., le Goff H., Weber M., Bruemmer B., Offermann M., Doble M., Wadhams P., Forsberg R., Hanson S., Skourup H., Gerland S., Nicolaus M., Metaxian J.-P., Grangeon J., Haapala J., Rinne E., Haas C., Heygster G., Jakobson E., Palo T., Wilkinson J., Kaleschke L., Claffey K., Elder B. \& Bottenheim J. 2008. Exploring Arctic Transpolar Drift during dramatic sea ice retreat. EOS, Transactions of the American Geophysical Union 89, 21-28.

Haas C., Pfaffling A., Hendricks S., Rabenstein L., Etienne J.-L. \& Rigor I. 2008. Reduced ice thickness in Arctic Transpolar Drift favors rapid ice retreat. Geophysical Research Letters 35, L17501, doi: 10.1029/2008GL034457.

Hanson K.J. 1961. The albedo of sea ice and ice islands in the Arctic Ocean basin. Arctic 14, 188-196.

Kay J.E., L'Ecuyer T., Gettelman A., Stephens G. \& O'Dell C. 2008. The contribution of cloud and radiation anomalies to the 2007 Arctic sea ice extent minimum. Geophysical Research Letters 35, L08503, doi: 10.1029/2008GL033451.

Kwok R. 2008. Summer sea ice motion from the $18 \mathrm{GHz}$ channel of AMSR-E and the exchange of sea ice between the Pacific and Atlantic sectors. Geophysical Research Letters 35, L03504, doi: 10.1029/2007GL032692.

Kwok R. \& Rothrock D.A. 2009. Decline in Arctic sea ice thickness from submarine and ICESat records: 1958-2008. Geophysical Research Letters 36, L15501, doi: 10.1029/ 2009 GL039035.

Langleben M.P. 1969. Albedo and degree of puddling of a melting cover of sea ice. Journal of Glaciology 8, 407-412.

Langleben M.P. 1971. Albedo of melting sea ice in the Southern Beaufort Sea. Journal of Glaciology 10, 101-104.

Markus T., Cavalieri D.J., Tschudi M.A. \& Ivanoff A. 2003. Comparison of aerial video and Landsat 7 data over ponded sea ice. Remote Sensing of Environment 86, 458-469.
Maslanik J., Drobot S., Fowler C., Emery W. \& Barry R. 2007. On the Arctic climate paradox and the continuing role of atmospheric circulation in affecting sea ice conditions. Geophysical Research Letters 34, L03711, doi: 10.1029/2006GL028269.

Maslanik J.A., Fowler C., Stroeve J., Drobot S., Zwally J., Yi D. \& Emery W. 2007. A younger, thinner Arctic ice cover: increased potential for rapid, extensive sea-ice loss. Geophysical Research Letters 34, L24501, doi: 10.1029/ 2007GL032043.

Neteler M. \& Mitasova H. 2002. Open Source GIS: a GRASS GIS approach. Norwell, MA, USA: Kluwer.

Pedersen C.A., Roeckner E., Lüthje M. \& Winther J.-G. 2009. A new sea ice albedo scheme including melt ponds for ECHAM5 general circulation model. Journal of Geophysical Research-Atmospheres 114, D08101, doi: 10.1029/2008JD010440.

Perovich D.K., Grenfell T.C., Light B., Elder B.C., Harbeck J., Polashenski C., Tucker W.B. \& Stelmach C. 2009.

Transpolar observations of the morphological properties of Arctic sea ice. Journal of Geophysical Research-Oceans 114, C00A04, doi: 10.1029/2008JC004892.

Perovich D.K., Grenfell T.C., Light B. \& Hobbs P.V. 2002. Seasonal evolution of the albedo of multiyear Arctic sea ice. Journal of Geophysical Research-Oceans 107, 8044, doi: 10.1029/2000JC000438.

Perovich D.K., Nghiem S.V., Markus T. \& Schweiger A. 2007. Seasonal evolution and interannual variability of the local solar energy absorbed by the Arctic sea ice-ocean system. Journal of Geophysical Research-Oceans 112, C03005, doi: 10.1029/2006JC003558.

Perovich D. \& Richter-Menge J.A. 2006. From points to poles: extrapolating point measurements of sea-ice mass balance. Annals of Glaciology 44, 188-192.

Perovich D.K., Richter-Menge J.A. \& Jones K.F. 2008. Sunlight, water, and ice: extreme Arctic sea ice melt during the summer of 2007. Geophysical Research Letters 35 , L1 1501, doi: 10.1029/2008GL034007.

Perovich D.K. \& Tucker W.B. III 1997. Arctic sea-ice conditions and the distribution of solar radiation during summer. Annals of Glaciology 25, 445-450.

Perovich D.K., Tucker W.B. III \& Ligett K.A. 2002. Aerial observations of the evolution of ice surface conditions during summer. Journal of Geophysical Research-Oceans 107, 8048, doi: 10.1029/2000JC000449.

Richter-Menge J.A., Perovich D.K., Elder B.C., Claffey K., Rigor I. \& Otmeyer M. 2006. Ice mass-balance buoys: a tool for measuring and attributing changes in the thickness of the Arctic sea-ice cover. Annals of Glaciology 44, 205-210.

Rothrock D., Yu Y. \& Maykut G. 1999. Thinning of the Arctic sea-ice cover. Geophysical Research Letters 26, 3469-3472.

Stroeve J., Serreze M., Drobot S., Gearheard S., Holland M., Maslanik J., Meier W. \& Scambos T. 2008. Arctic sea ice extent plummets in 2007. EOS, Transactions of the American Geophysical Union 89, 13-14. 
Tschudi M.A., Curry J.A. \& Maslanik J.A. 1997.

Determination of areal surface-featured coverage in the Beaufort Sea using aircraft video data. Annals of Glaciology $25,434-438$.

Tschudi M.A., Curry J.A. \& Maslanik J.A. 2001. Airborne observations of summertime surface features and their effect on surface albedo during FIRE/SHEBA. Journal of Geophysical Research-Atmospheres 106, 15 335-15 344.

Tschudi M.A., Maslanik J.A. \& Perovich D.K. 2008. Derivation of melt pond coverage on Arctic sea ice using MODIS observations. Remote Sensing of Environment 112, 2605-2614.

Tucker W.B., Gow A.J., Meese D.A. \& Bosworth H.W. 1999. Physical characteristics of summer sea ice across the Arctic Ocean. Journal of Geophysical Research-Oceans 104, 14891504.

Vihma T., Jaagus J., Jakobson E. \& Palo T. 2008.

Meteorological conditions in the Arctic Ocean in spring and summer 2007 as recorded on the drifting ice station Tara. Geophysical Reseach Letters 35, L18706, doi: 10.1029/ 2008 GL034681.

Wang J., Zhang J., Watanabe E., Ikeda M., Mizobata K., Walsh J.E., Bai X. \& Wu B. 2009. Is the Dipole Anomaly a major driver to record lows in Arctic summer sea ice extent? Geophysical Research Letters 36, L05706, doi: 10.1029/2008GL036706.

Yackel J.J., Barber D.G. \& Hanesiak J.M. 2000. Melt ponds on sea ice in the Canadian Archipelago. 1. Variability in morphological and radiative properties. Journal of Geophysical Research-Oceans 105, 22 049-22 060.

Zhang J., Lindsay R., Steele M. \& Schweiger A. 2008. What drove the dramatic retreat of Arctic sea ice during summer 2007? Geophysical Research Letters 35, L11505, doi: 10.1029/ 2008 GL034005. 